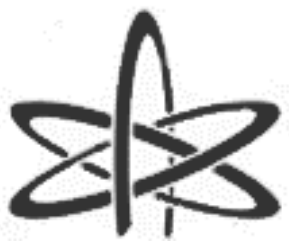

BJRS
BRAZILIAN JOURNAL

OF

RADIATION SCIENCES

08-01A (2020) 01-12

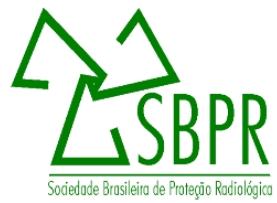

\title{
Análise estátistica da frequência de micronúcleos em diferentes doses absorvidas de raios gama
}

\author{
Silva $^{\text {a,b }}$ L. M., Silva ${ }^{a}$ J. C. G., Nascimento ${ }^{a, b}$ A. M., Lima ${ }^{a, b}$ J. C. F., Hwang ${ }^{a}$ S., \\ Mendes $^{\mathrm{a}, \mathrm{c}}$ M. E., Lima ${ }^{\mathrm{a}}$ F. F. \\ ${ }^{a}$ CRCN/NE, Av. Prof. Luís Freire, 200 - Curado, Recife - PE, 50730-120 \\ ${ }^{b}$ UFPE, Av. Prof. Moraes Rego, 1235 - Cidade Universitária, Recife - PE, 50670-901 \\ ${ }^{c}$ UNIBRA, R. Padre Inglês, 257 - Boa Vista, Recife - PE, 50050-230
}

fflima@cnen.gov.br

\section{RESUMO}

A técnica de micronúcleos (MN) com bloqueio da citocinese celular (CBMN - Cytokinesis-Block Micronucleus) é uma técnica da biodosimetria que, por ser mais rápida na análise que a técnica de dicêntricos, possibilita realizar triagens entre indivíduos expostos significativamente ou não à radiação ionizante em casos de acidentes radiológicos em massa. Entretanto, para isso é necessário que curvas de calibração dose-resposta sejam previamente estabelecidas pelo laboratório que se propuser a realizar serviços de dosimetria biológica. $O$ objetivo desse trabalho é analisar as frequências de MN devido à irradiação de sangue in vitro com raios gama para compor a curva de calibração dose-resposta do Laboratório de Dosimetria Biológica (LDB) do Centro Regional de Ciências Nucleares do Nordeste (CRCN-NE/CNEN). As amostras foram irradiadas de forma a resultar em valores de doses absorvidas de $0,5 \mathrm{~Gy}$ a 2,0Gy. Após a irradiação, as amostras passaram duas horas em estufa de $\mathrm{CO}_{2}$ para reparação das células, depois seguiram para a cultura de linfócitos conforme protocolo descrito pela IAEA. As análises estatísticas foram realizadas por meio do teste u de Papworth a fim de verificar se a distribuição de células com MN se ajustam ao modelo de Poisson. As frequências de micronúcleo, bem como sua distribuição, estão se apresentando de acordo com o esperado e serão utilizados na curva de calibração doseresposta de MN para radiação gama do LDB/CRCN-NE/CNEN. Os experimentos serão replicados com outras doses e outros voluntários, tornando a curva mais robusta e viabilizando a comparação da resposta nas células de indivíduos em diferentes faixa etárias e gêneros. 


\begin{abstract}
The micronucleus (MN) with blocking cell cytokinesis technique (CBMN - Cytokinesis-Block Micronucleus) is a biodosimetry technique that, because it is faster in analysis than the dicentric technique, makes it possible to perform screens among individuals significantly or not exposed to ionizing radiation in cases of radiological accidents involving many individuals. However, for this it is necessary that dose-response calibration curves are previously established by the laboratory that proposes to perform biological dosimetry services. The aim of this work is to analyze the MN frequencies due to in vitro blood irradiation with gamma rays to compose the doseresponse calibration curve of the Laboratory of Biological Dosimetry (LDB) of the Centro Regional de Ciências Nucleares do Nordeste (CRCN-NE / CNEN). The samples were irradiated in order to result in absorbed dose values ranging from $0.5 \mathrm{~Gy}$ to $2.0 \mathrm{~Gy}$. After irradiation, the samples spent two hours in a $\mathrm{CO}_{2}$ stove to repair the cells, then proceeded to the lymphocyte culture according to the protocol described by the IAEA. Statistical analyzes were performed using the Papworth u test in order to verify whether the distribution of cells with MN fits the Poisson model. The micronucleus frequencies, as well as their distribution, are showing up as expected and will be used in the MN dose-response calibration curve for gamma radiation of the LDB / CRCN-NE / CNEN . The experiments will be replicated with other doses and volunteers, making the curve more robust and enabling the comparison of the response in the cells of individuals in different age and genders groups.
\end{abstract}

Keywords: Biodosimetry, Micronucleous, gamma rays. 


\section{INTRODUÇÃO}

A absorção de radiação ionizante pelas células pode interromper diretamente a estrutura atômica de moléculas biológicas. Entretanto, pode haver a interação indireta por meio da radiólise da água, produzindo outras espécies químicas reativas, os chamados radicais livres, que podem danificam os ácidos nucleicos, proteínas e lipídios [1]. Presume-se que os danos causados no genoma humano por radiação de alta energia são cerca de um terço direto e dois terços indiretos [2].

A alteração cromossômica surge do resultado de um DNA mal reparado ou a partir de DSB. Para a dosimetria biológica, a alteração cromossômica fornece uma medida do dano e, com isso, torna-se uma resposta biológica muito sensível à dose absorvida de radiação. As alterações cromossômicas são mais comumente identificadas através de duas técnicas: a análise citogenética convencional de cromossomos dicêntrico $[3,4]$ e a técnica de micronúcleos $(\mathrm{MN})$ com bloqueio da citocinese celular (CBMN, Cytokinesis-Block Micronucleus) [5].

A técnica de $\mathrm{MN}$ em linfócitos do sangue periférico com bloqueio da citocinese celular foi desenvolvida por Fenech e Morley, em 1985, sendo um método confiável para quantificar quebras cromossômicas. Os MNs surgem durante a exposição à vários agentes clastogênicos e resultam também do DNA mal reparado ou de DSB. Os MNs podem resultar de pequenos fragmentos acêntricos ou conter cromossomos inteiros, como dicêntricos, que não estão incorporados aos núcleos das células filhas durante a divisão celular. Eles estão presentes no envoltório nuclear, por essa razão, eles aparecem como pequenos núcleos - micronúcleos - no citoplasma de forma separada dos núcleos das células filhas [5,6].

As análises das alterações cromossômicas são feitas em linfócitos circulantes e os resultados são convertidos em dose absorvida usando curvas de calibração dose-resposta previamente estabelecidas. Cada ponto da curva de calibração representa uma média da dose absorvida pelos linfócitos irradiados. Isso é aproximado para uma média de dose de corpo inteiro considerando que os linfócitos são amplamente móveis e distribuídos pelo corpo. Com a curva de calibração gerada e estabelecida, torna-se possível estimar a dose absorvida pelo organismo do indivíduo exposto à radiação ionizante $[4,7]$.

Matematicamente, as curvas de calibração representam a quantidade de dose absorvida pelo organismo humano em relação ao número (ou resposta) de micronúcleos presentes nos linfócitos 
provenientes do sangue periférico humano. É representada por uma função matemática da forma: Y $=\mathrm{C}+\alpha \mathrm{D}+\beta \mathrm{D}^{2}$ para radiação de baixa LET (raios $\mathrm{X}$ e radiação gama), onde $\alpha$ e $\beta$ são os coeficientes linear e quadrático, respectivamente, e que determinam a forma e inclinação da curva, Y é a frequência da alteração, C determina o número espontâneo (background) de micronúcleo e D corresponde à dose absorvida de radiação $[4,8]$.

Devido à boa confiabilidade e reprodutibilidade, o ensaio de MN tornou-se um padrão para testes de toxicologia genética em células humanas e de mamíferos em geral [9]. No domínio da proteção radiológica, o ensaio de $\mathrm{MN}$ em linfócitos do sangue periférico é uma ferramenta apropriada de dosimetria biológica para avaliar exposição in vivo à radiação, em acidentes em grande escala, servindo para a triagem dos indivíduos mais severamente expostos [4,5]. Além disso, é apropriado para avaliar indivíduos ocupacionalmente expostos em serviços de medicina nuclear e de indivíduos expostos acidentalmente, podendo também ser utilizado para avaliar in vitro a radiossensibilidade e suscetibilidade ao câncer [5].

Assim, o objetivo deste trabalho foi implementar no Laboratório de Dosimetria Biológica (LDB) do Centro Regional de Ciências Nucleares do Nordeste (CRCN-NE/CNEN) uma curva de calibração dose-resposta preliminar para $\mathrm{MN}$ que poderá ser utilizada na avaliação das doses absorvidas por trabalhadores, pacientes e indivíduos expostos à radiação gama.

\section{MATERIAIS E MÉTODOS}

A pesquisa foi realizada no Laboratório de Dosimetria Biológica do Centro Regional de Ciências Nucleares do Nordeste - CRCN-NE, e faz parte de um projeto aprovado para coleta de dados pelo Comitê de Ética envolvendo pesquisas com seres humanos da Universidade Federal de Pernambuco sob o número de CAAE 09186813.7.0000.5208 e do parecer consubstanciado 269.483. Um voluntário saudável foi selecionado após anamnese e assinatura do Termo de Consentimento Livre e Esclarecido.

\subsection{Coleta e irradiação das amostras}

Foram coletadas amostras de sangue periférico $(10 \mathrm{ml})$ de uma doadora saudável e não fumante por coleta de sangue a vácuo. Cada amostra de sangue foi separada em duas alíquotas de $5 \mathrm{ml}$, 
sendo uma considerada controle (não irradiada) e mantida à temperatura ambiente do laboratório $\left(20-22{ }^{\circ} \mathrm{C}\right)$, e a outra alíquota, considerada amostra irradiada. As amostras irradiadas foram

expostas a uma fonte de ${ }^{60} \mathrm{Co}$ (irradiador Gammacel 220) localizada no Departamento de Energia Nuclear (DEN/UFPE) (temperatura da sala de $\sim 22{ }^{\circ} \mathrm{C}$ ) com taxas de KERMA no ar de 1,271 Gy/h com incerteza de $2 \%$ no ponto de irradiação.

O fator de conversão da unidade KERMA no ar para dose absorvida em tecido mole é a razão entre os coeficientes de massa de absorção de energia. Numericamente, isso foi obtido pela multiplicação do valor de KERMA no ar por 1,10 para raios $\gamma$ de fontes de ${ }^{60}$ Co. Há também uma diferença entre os fatores de conversão de tecidos moles para o sangue, entretanto, para radiações de baixa LET essa diferença é desprezível [9]. As amostras foram irradiadas com 4 diferentes valores de dose absorvida variando entre $0,5 \mathrm{~Gy}$ a $2 \mathrm{~Gy}$.

\subsection{Cultivo de células e preparação das lâminas}

Antes do início do cultivo celular, as amostras irradiadas e controle permaneceram na estufa a $37^{\circ} \mathrm{C}$, por 2 horas, tempo necessário para que os mecanismos de reparação celular pudessem atuar, sendo esse um procedimento indicado para construções de curvas de calibração in vitro [4].

As preparações citológicas para as análises cromossômicas foram obtidas a partir de cultura de linfócitos, onde foram adicionados $4 \mathrm{ml}$ de meio RPMI 1640 (Gibco) suplementado com $1 \mathrm{ml}$ de soro bovino fetal (Gibco), 0,1 ml de fitohemaglutinina (Sigma - Aldrich) e 0,5 ml de sangue total nos frascos de cultura. Em seguida, os frascos foram mantidos na estufa a $37^{\circ} \mathrm{C}$, por 72 horas. Após 24 horas, foi adicionado aos frascos $0,02 \mathrm{ml}$ de citocalasina B na concentração de 0,0016\% (Sigma - Aldrich).

Ao completar 72 horas de cultivo, o material foi centrifugado por 10 minutos a $180 \mathrm{~g}$, o sobrenadante foi desprezado e foi realizado o choque hipotônico adicionando $7 \mathrm{ml} \mathrm{de} \mathrm{KCl}$ e, em seguida, os tubos centrifugados. Ao término, o sobrenadante foi retirado e adicionado o fixador metanol:ácido acético (10:1) diluído na solução de Ringer na proporção (1:1) até completar $8 \mathrm{ml}$. Para a preparação das lâminas, foram realizadas centrifugações e trocas de fixador na mesma proporção (10:1) até que o conteúdo da cultura estivesse transparente. 
Após o processo de fixação foram confeccionadas lâminas a partir do precipitado de células ressuspenso em $0,5-0,75 \mathrm{ml}$ de solução fixadora. O precipitado de células ressuspenso foi gotejado em dois pontos em cada lâmina e essas foram colocadas para secar a temperatura ambiente durante 24 h. Em seguida, as lâminas foram coradas com Giemsa a $5 \%$ durante 20 min para posterior análise microscópica.

\subsection{Análise Microscópica}

A contagem dos micronúcleos foi realizada diretamente no microscópio óptico (Leica DM 500). As lâminas foram examinadas na sua totalidade e ao menos 1000 células binucleadas viáveis foram contadas por cada amostra. Os critérios seguidos foram estabelecidos por Fenech [9] e consideram células binucleadas viáveis aquelas cujo ambos os núcleos apresentarem tamanhos, coloração e intensidade de coloração iguais, e membranas nucleoplasmáticas intactas; não serão contabilizadas células binucleadas com núcleos sobrepostos onde a barreira de suas membranas não são distinguíveis. Da mesma forma, a IAEA [4] também define a aceitação de MN visualizados em células binucleadas como, MN devem ter de 1/6 a 1/3 do diâmetro dos núcleos principais, não são refringentes e possuem uma coloração igual ou levemente mais forte que os núcleos principais, e não devem se sobrepor a um dos núcleos assim sendo a membrana micronuclear deve ser distinta da membrana nuclear conforme observado na Figura 1.

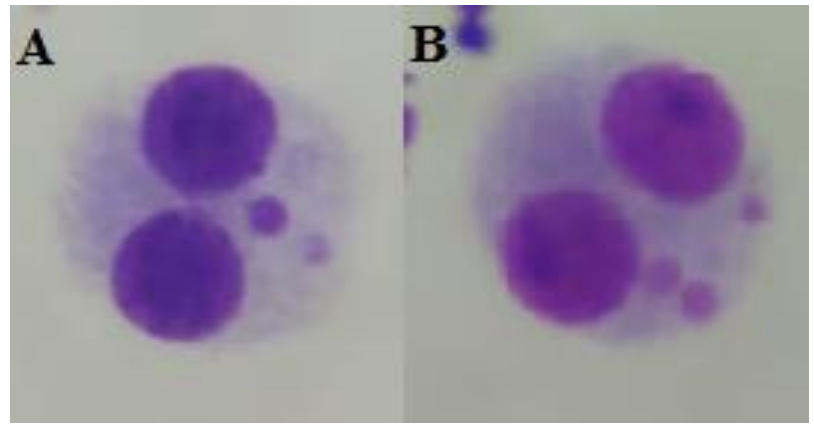

Figura 1: Células binucleadas com dois micronúcleos $(A)$ e com três micronúcleo (B) 


\subsection{Análise estatística}

Ao término da contagem das células foram realizados cálculos estatísticos. Como os métodos de ajuste de curva se baseiam em modelos estatísticos de Poisson, se deve verificar se a distribuição de células com MN se ajustam ou não a distribuição de Poisson para cada dose utilizada para compor a curva de calibração por meio do teste u de Papworth $[9,10]$. A estatística de teste u é uma unidade normalizada do índice de dispersão $\left(\sigma^{2} / y\right)$ onde valores de u superiores a 1,96 indicam sobredispersão significativa e os valores de $\mathrm{u}<-1,96$ indicam a subdispersão significativa [9].

Com o auxílio do programa para ajuste de curvas, o Dose Estimate [11], foi obtida a curva de calibração dose-resposta para radiação de baixa LET, sendo determinados os coeficientes (C, $\alpha$ e $\beta$ ).

\section{RESULTADOS E DISCUSSÃO}

Foram analisadas mais de 17 mil células binucleadas viáveis. A frequência de MN (y) para a amostra controle (background), conforme se observa na Tabela 1, está de acordo com a literatura, que compreende uma faixa de frequência entre 0 a 40 MN por 1000 células binucleadas [4].

Tabela 1: Verificação da frequência e distribuição celular de micronúcleos.

\begin{tabular}{ccccccccccccc}
\hline & & \multicolumn{1}{c}{ Distribuição celular } & & & & & \\
Dose & Total & $\mathbf{M N}$ & $\mathbf{0 M N}$ & $\mathbf{1 M N}$ & $\mathbf{2 M N}$ & $\mathbf{3 M N}$ & $\mathbf{4 M N}$ & $\mathbf{y}$ & $\mathbf{S E} \mathbf{y}$ & $\boldsymbol{\sigma}^{2} / \mathbf{y}$ & $\mathbf{S E} \boldsymbol{\sigma}^{2} / \mathbf{y}$ & $\mathbf{U}$ \\
\hline $0^{*}$ & & & & & & & & & & & & \\
0,5 & 1590 & 19 & 5982 & 17 & 1 & 0 & 0 & 0,003 & 0,001 & 1,1 & 0,018 & 5,76 \\
0,75 & 4070 & 272 & 3811 & 247 & 11 & 0 & 0 & 0,021 & 0,002 & 1,1 & 0,018 & 5,41 \\
1 & 4000 & 344 & 3681 & 297 & 19 & 3 & 0 & 0,048 & 0,006 & 1,03 & 0,035 & 0,859 \\
2 & 2000 & 387 & 1684 & 255 & 54 & 4 & 3 & 0,194 & 0,004 & 1,04 & 0,022 & 1,64 \\
\hline
\end{tabular}

* referente ao sangue controle, (Y) frequência de Mn, (var/Y) indice de dispersão, (u) teste u.

Foi possível observar a relação entre a dose absorvida e a frequência de $\mathrm{MN}$, confirmando que, com o aumento da dose absorvida, as frequências de MN também se elevam. Esse crescimento demonstrou uma dependência linear do rendimento de MN com a dose. Além disso, com o aumento da dose é possível observar a presença de células binucleadas com mais de um MN.

Foram testadas as concordâncias das distribuições celulares dos MN com a distribuição de Poisson em todas as doses absorvidas, usando o índice de dispersão $\left(\sigma^{2} / \mathrm{y}\right)$ e o teste $u$ (Tabela 1$)$. O 
teste $u$ de Papworth é uma unidade normalizada do índice de dispersão que, para uma distribuição perfeita de Poisson a razão precisa ser igual a um. Entretanto, no intervalo de confiança de 95\%, os valores de $u$ podem variar entre $\pm 1,96$, onde valores de $\mathrm{u}$ acima de 1,96 indicam sobredispersão significativa e valores de u menor que 1,96 indicam subdispersão significativa [4].

Os valores do teste $u$ deste trabalho demonstraram sobredispersão na maioria das doses (Tabela 1). Esta sobredispersão observada parece estar relacionada com os fragmentos acêntricos, uma vez que alguns $\mathrm{MN}$ são formados quando esses fragmentos não são incorporados pelo núcleo das células filhas durante a divisão celular e os fragmentos celulares têm uma distribuição sobredispersa $[4,12,13]$.

Na tabela 2 são comparados os valores do teste u de outros trabalhos [14-17] que também utilizaram radiação gama. Observa-se uma sobredispersão em grande parte das doses, indicando conformidade deste trabalho com a literatura.

Tabela 2: Frequência e teste u de diversos trabalhos da literatura.

\begin{tabular}{|c|c|c|c|c|c|c|c|c|c|c|}
\hline & \multicolumn{2}{|c|}{$\begin{array}{c}\text { Este } \\
\text { trabalho }\end{array}$} & \multicolumn{2}{|c|}{$\begin{array}{c}\text { Senthamizhchelvan, } \\
2008\end{array}$} & \multicolumn{2}{|c|}{$\begin{array}{c}\text { Antunes, } \\
2014\end{array}$} & \multicolumn{2}{|c|}{$\begin{array}{c}\text { Rastkhah, } \\
\text { 2016** }\end{array}$} & \multicolumn{2}{|c|}{$\begin{array}{l}\text { Nairy, } \\
2017\end{array}$} \\
\hline Dose & $\mathbf{y}$ & $\mathbf{u}$ & $\mathbf{Y}$ & $\mathbf{U}$ & $\mathbf{y}$ & $\mathbf{u}$ & $\mathbf{Y}$ & $\mathbf{u}$ & $\mathbf{y}$ & $\mathbf{u}$ \\
\hline 0* & 0,003 & 5,76 & 0,012 & 2,31 & 0,012 & 6,23 & 0,011 & 7,54 & 0,017 & $-0,39$ \\
\hline 0,5 & 0,021 & 5,41 & 0,045 & 7,73 & 0,027 & 11,16 & 0,066 & 7,86 & 0,067 & 2,47 \\
\hline 0,75 & 0,048 & 0,859 & 0,064 & 9,33 & 0,041 & 10,25 & & & & \\
\hline 1 & 0,067 & 1,64 & 0,105 & 8,72 & 0,055 & 6,7 & 0,120 & 11,1 & 0,136 & 11,08 \\
\hline 2 & 0,194 & 7,64 & 0,259 & 9,44 & 0,144 & 10,45 & 0,279 & 8,84 & 0,29 & 7,15 \\
\hline
\end{tabular}

* referente ao sangue controle, (Y) frequência, (u) teste u. ** Frequências e distribuições de MN nas células binucleadas de mulheres entre 20 a 34 anos.

Na figura 2 estão dispostos os coeficientes $(C, \alpha$ e $\beta)$ da curva de calibração dose resposta preliminar que foram obtidos com a ajuda do programa Dose Estimate [11] para radiação de baixa LET e ajustada para a função linear quadrática. Observa-se que o valor de $\alpha$ é maior que o $\beta$ e esta tendência também é observada em outros estudos da literatura (Tabela 3) [14-17]. 


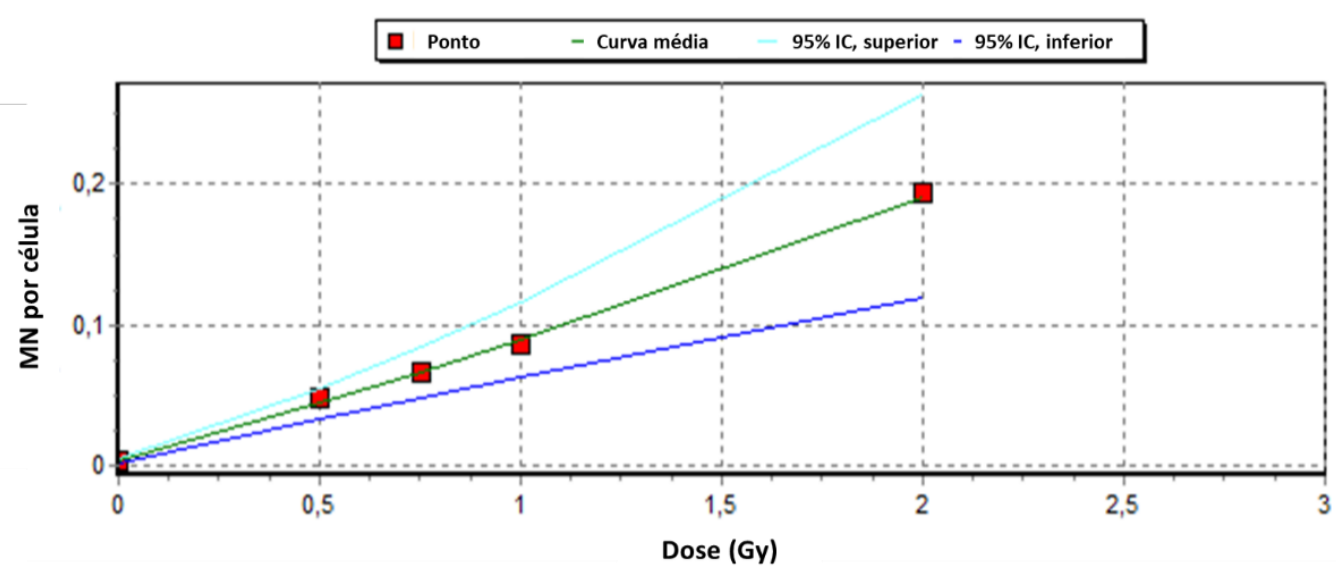

Figura 2. Curva de calibração ajustadas para a função quadrática obtida pelo Programa Dose Estimate. *IC-Intervalo de confiança.

Tabela 3: Curvas de calibração para radiação gama referentes na literatura.

\begin{tabular}{lcccccc}
\hline & $\mathbf{C}$ & SE C & $\boldsymbol{\alpha}$ & SE $\boldsymbol{\alpha}$ & $\boldsymbol{\beta}$ & SE $\boldsymbol{\beta}$ \\
\hline Este trabalho & 0,0038 & 0,0012 & 0,0668 & 0,0077 & 0,0274 & 0,0043 \\
Senthamizhchelvan, & 0,0145 & 0,0029 & 0,0311 & 0,0095 & 0,0464 & 0,0034 \\
2008 & 0,0122 & 0,0010 & 0,0241 & 0,0023 & 0,0193 & 0,0007 \\
Antunes, 2014 & 0,0122 & 0,0017 & 0,0827 & 0,0060 & 0,0276 & 0,0019 \\
Rastkhah, 2016* & & & 0,068 & 0,008 & 0,032 & 0,002 \\
Nairy, 2017 & & & \\
SE. Erro padrão, *Frequências e distribuições de MN nas células binucleadas de mulheres entre 20 a 34 anos.
\end{tabular}

De acordo com Romm et al. (2013), as curvas de calibração dose-resposta de MN apresentam os coeficientes lineares $(\alpha)$ com valores maiores, ou seja, mais significativo na estimativa de dose, do que os coeficientes quadráticos $(\beta)$, logo interação única da radiação tem a maior contribuição na formação de $\mathrm{MN}$, mesmo mudando a qualidade da radiação, a forma de análise (manual ou automática) e o total de células analisadas [18]. 


\section{CONCLUSÕES}

As frequências de micronúcleos, bem como sua distribuição, estão se apresentando de acordo com o esperado e serão utilizados na curva de calibração dose-resposta de MN para radiação gama do Laboratório de Dosimetria Biológica do CRCN/NE. A mesma será complementada com outras doses absorvidas até $5 \mathrm{~Gy}$, totalizando 10 pontos de dose absorvida, e os experimentos serão replicados com outros voluntários, tornando a curva mais robusta e viabilizando a comparação da resposta nas células de indivíduos em diferentes faixa etárias e gêneros.

\section{REFERÊNCIAS}

[1] AZZAM, E. I. ; Jay-Gerin, J. P. ; Pain, D. Ionizing radiation-induced metabolic oxidative stress and prolonged cell injury. Cancer letters, v. 327, n. 1-2, p. 48-60, 2012.

[2] ALIZADEH, E.; ORLANDO, T. M.; SANCHE, L. Biomolecular damage induced by ionizing radiation: the direct and indirect effects of low-energy electrons on DNA. Annual review of physical chemistry, v. 66, p. 379-398, 2015.

[3] POHL-RÜLING, J. Low level dose induced chromosome aberrations in human blood lymphocytes. Radiation Protection Dosimetry, v. 45, n. 1-4, p. 623-627, 1992.

[4] International Atomic Energy Agency, IAEA Cytogenetic dosimetry: applications inpreparedness for, and response to radiation emergencies, EPR-Biodosimetry,2011.

[5] THIERENS, H. ; VRAL, A. The micronucleus assay in radiation accidents, AnnaliDell Istituto Superiore Di Sanita, 45(3):260-264, 2009.

[6] FENECH, M. The in vitro micronucleus technique. Mutation Research/Fundamental and Molecular Mechanisms of Mutagenesis, v. 455, n. 1-2, p. 81-95, 2000.

[7] ROY, L. et al. Effect of lymphocytes culture variations on the mitotic index and on the dicentric yield following gamma radiation exposure. Radiation protection dosimetry, $v$. 151, n. 1, p. 135-143, 2012. 
[8] LLOYD, D. C.; DOLPHIN, G. W. Radiation-induced chromosome damage in human lymphocytes. Occupational and Environmental Medicine, v. 34, n. 4, p. 261-273, 1977.

[9] FENECH M, Cytokinesis-block micronucleus cytome assay. Nat. Protoc. 2, 1084-1104. 2007

[10] ACHARYA S. ; SANJEEV G. ; BHAT N. N. ; SIDDAPPA K. ; NARAYANA Y. The effect of electron and gamma irradiation on the induction of micronuclei in cytokinesisblocked human blood lymphocytes. Radiation Environmental Biophys, 48:197-203, 2009.

[11] AINSBURY, E. A.; LLOYD, D. C. Dose estimation software for radiation biodosimetry. Health Physics, v. 98, n. 2, p. 290-295, 2010.

[12] KÖKSAL, G. ; DALCI, D. Ö. ; PALA, F. S. Micronuclei in human lymphocytes: the Co60 gamma-ray dose-response. Mutation Research/Environmental Mutagenesis and Related Subjects, v. 359, p. 151-157, 1996.

[13] MENDES, M. E. ; MENDONÇA, J. C. G. ; BARQUINERO, J. F. ; HIGUERAS, M. ; GONZALEZ, J. E. ; ANDRADE, A. M. G. ; SILVA, L. M. ; NASCIMENTO, A. M. S. ; LIMA, J. C. F. ; SILVA, J. C. G. ; HWANG, S. ; MELO, A. M. M. A. ; SANTOS, N. ; LIMA, F. F. Comparative study of micronucleus assays and dicentric plus ring chromosomes for dose assessment in particular cases of partial-body exposure. Int J Radiat Biol, v. 95, n. 8, p. 1058-1071, 2019.

[14] SENTHAMIZHCHELVAN, S. ; PANT, G.S. ; RATH G.K. ; JULKA, P.K. ; NAIR, O. ; PRABHAKAR, R. ; MALHOTRA, A. Biological estimation of dose in hemi-body irradiation of cancer patients by cytogenetic analysis. Health physics, v. 94, n. 2, p. $112-$ $117,2008$.

[15] ANTUNES, A. C. ; MARTINS, V. ; CARDOSO, J. ; SANTOS, L. ; GIL, O.M. The cytokinesis-blocked micronucleus assay: dose estimation and inter-individual differences in the response to $\gamma$-radiation. Mutation Research/Genetic Toxicology and Environmental Mutagenesis, v. 760, p. 17-22, 2014. 
[16] RASTKHAH, E. ; ZAKERI, F. ; GHORANNEVISS, M. ; RAJABPOUR, M.R. ; FARSHIDPOUR, M.R. ; MIANJI, F. ; BAYAT, M. The cytokinesis-blocked micronucleus assay: dose-response calibration curve, background frequency in the population and dose estimation. Radiation and environmental biophysics, v. 55, n. 1, p. 41-51, 2016.

[17] NAIRY, R. K ; BHAT, N. N ; SANJEEV, G. ; YEROL, N. Dose-response study using micronucleus cytome assay: a tool for biodosimetry application. Radiation protection dosimetry, v. 174, n. 1, p. 79-87, 2017.

[18] ROMM, H. ; BARNARD, S. ; BOULAY-GREENE, H. ; DE AMICIS, A. ; DE SANCTIS, S. ; FRANCO, M. ; HERODIN, F. ; JONES, A. ; KULKA, U. ; LISTA, F. ; MARTIGNE, P. ; MOQUET , J. ; OESTREICHER, U. ; ROTHKAMM, K. ; THIERENS, H. ; VALENTE, M. ; VANDERSICKEL, V. ; VRAL, A. ; BRASELMANN, H. ; MEINEKE, V. ; ABENDH, M. ; BEINKE, C. Laboratory intercomparison of the cytokinesis-block micronucleus assay. Radiation research, v. 180, n. 2, p. 120-128, 2013. 